\title{
Exercise-associated DNA methylation change in skeletal muscle and the importance of imprinted genes: a bioinformatics meta-analysis
}

\author{
William M Brown
}

- Additional material is published online only. To view please visit the journal online (http://dx.doi.org/10.1136/ bjsports-2014-094073).

\section{Correspondence to} Dr William M Brown, Department of Sport Science and Physical Activity, Faculty of Education and Sport, Health Epigenetics and Ageing Laboratory (HEAL), Institute of Sport and Physical Activity Research, University of Bedfordshire, Polhill Avenue, Bedford, Bedfordshire, MK41 9EA, UK;

epigenomics@icloud.com

Accepted 18 February 2015

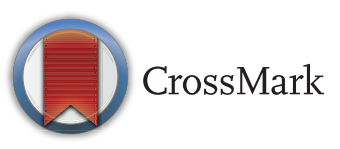

To cite: Brown WM. $\mathrm{Br}$ Sports Med Published Online First: [please include Day Month Year] doi:10.1136/ bjsports-2014-094073

\section{ABSTRACT}

Background Epigenetics is the study of processesbeyond DNA sequence alteration-producing heritable characteristics. For example, DNA methylation modifies gene expression without altering the nucleotide sequence. A well-studied DNA methylation-based phenomenon is genomic imprinting (ie, genotypeindependent parent-of-origin effects).

Objective We aimed to elucidate: (1) the effect of exercise on DNA methylation and (2) the role of imprinted genes in skeletal muscle gene networks (ie, gene group functional profiling analyses).

Design Gene ontology (ie, gene product elucidation)/ meta-analysis.

Data sources 26 skeletal muscle and 86 imprinted genes were subjected to g:Profiler ontology analysis. Meta-analysis assessed exercise-associated DNA methylation change.

Data extraction g:Profiler found four muscle gene networks with imprinted loci. Meta-analysis identified 16 articles (387 genes/1580 individuals) associated with exercise. Age, method, sample size, sex and tissue variation could elevate effect size bias.

Data synthesis Skeletal muscle gene networks including imprinted genes reported. Exercise-associated effect sizes were calculated by gene. Age, method, sample size, sex and tissue variation were moderators. Results Six imprinted loci (RB1, MEG3, UBE3A, PLAGL1, SGCE, INS) were important for muscle gene networks, while meta-analysis uncovered five exerciseassociated imprinted loci (KCNQ1, MEG3, GRB10, L3MBTL 1, PLAGL 1). DNA methylation decreased with exercise ( $60 \%$ of loci). Exercise-associated DNA methylation change was stronger among older people (ie, age accounted for $30 \%$ of the variation). Among older people, genes exhibiting DNA methylation decreases were part of a microRNA-regulated gene network functioning to suppress cancer.

Conclusions Imprinted genes were identified in skeletal muscle gene networks and exercise-associated DNA methylation change. Exercise-associated DNA methylation modification could rewind the 'epigenetic clock' as we age.

Trial registration number CRD42014009800.

\section{INTRODUCTION}

British developmental biologist Sir Conrad H Waddington introduced the term 'epigenetics' as a science of development from genotype to phenotype. ${ }^{1}$ However, the term 'epigenetics' had an independent origin and meaning, which led to a conflation of terms. ${ }^{2}$ Recall Waddington's use of the term 'epigenetics' to refer to the causal processes of development, with an emphasis on interactions among genes and between genes and the environment. In contrast, $\mathrm{Nanney}^{3}$ used 'epigenetic' in 1958 to describe a system of cellular heredity that was not based on DNA sequence.

Most molecular biologists use the term epigenetic to mean the study of heritable changes in gene expression or cellular phenotype caused by mechanisms other than changes in the underlying DNA sequence-hence the name epi- (Greek for 'over', 'above' or 'outer') -genetics. Examples of such changes are DNA methylation and histone modifications (figure 1), both of which can regulate gene expression without altering the underlying DNA sequence. One well-studied epigenetic phenomenon based on DNA methylation in mammals (and notably humans) is genomic imprinting. ${ }^{4}$ One purpose of this review is to introduce this term to the sports and exercise medicine/physiotherapy community and explain its importance.

\section{Genomic imprinting}

Genomic imprinting is defined as genotype-independent parent-of-origin gene expression. Specifically, for most genes we inherit two working parental copies. However, in the case of imprinted genes, an epigenetic tag (via DNA methylation) is placed on either the maternal or paternal copy rendering the other inactive. Such parent-of-origin gene expression is mediated by epigenetic modifications which differ between the two parentally derived chromosomes. ${ }^{5}$ Approximately $1 \%$ of the human genome is imprinted. ${ }^{67}$ Despite their rarity, imprinted genes are of great medical importance. Studies of metabolic growth and neurodevelopmental disorders have shown that imprinted genes are absolutely essential for healthy development. ${ }^{8-13}$ Furthermore, epigenetic dysregulation in imprinted genes-which often have growth-enhancing and tumour suppressor functions - predict disease and cancer outcomes.

Once epigenetic mechanisms emerged during mammalian evolution (eg, genomic imprinting), a source of environmental information (ie, parent-of-origin of a gene) was transmitted transgenerationally. Imprinting machinery (eg, DNA methylation, see figure 1-a type of silencer at a gene's promoter-places marks on a gene when the gametes are produced) allowed for biased gene expression in the subsequent generation (ie, monoallelic gene expression).

The realisation that the environment has profound influences on the epigenome has led to a strong hypothesis that exercise can also affect DNA methylation and have long-term health outcomes. 


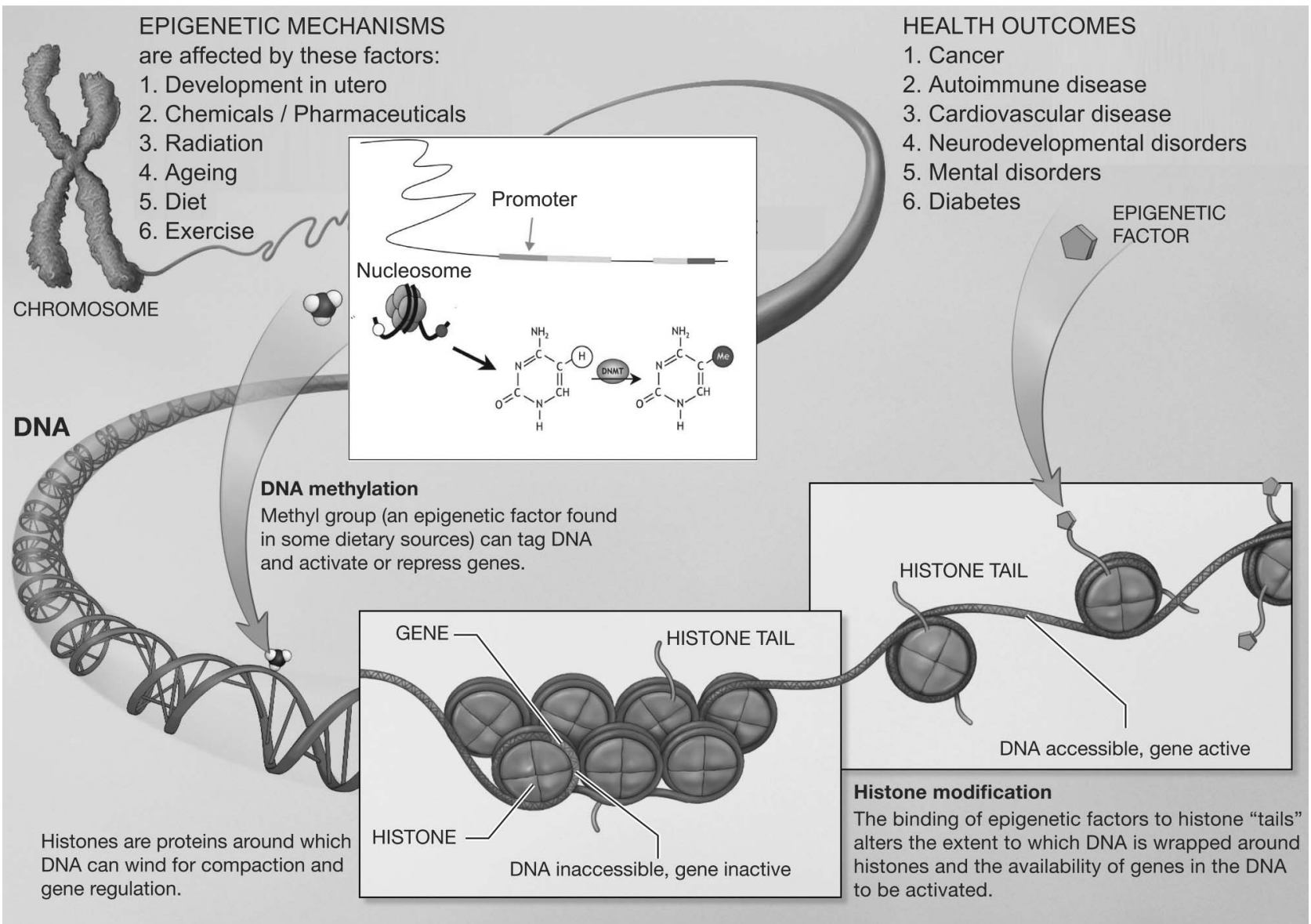

Figure 1 DNA methylation: DNA methylation occurs when methyl groups 'tag' DNA and activate or repress gene expression. DNA methyltransferase is a catalyst, which transfers methyl groups to DNA. Silencing of a gene activity can occur if the hydrogen $(\mathrm{H})$ molecule of cytosine $(\mathrm{C})$ is replaced by a methyl (Me) group at a gene's promoter. Histones: Histones are proteins around which DNA can wind for compaction and histone modification can regulate gene activity. Both epigenetic processes (ie, DNA methylation and histone modifications) affect health resulting in cancer, autoimmune disease, neurological disorders or diabetes. Image modified from the National Institutes of Health, Benjamin I. Laufer and Forluvoft.

Specifically, we propose that the same mechanism that controls genomic imprinting in mammals (ie, DNA methylation) allows for phenotypic modification and the possibility of multiple sources of environmental information (eg, exercise, nutrition) to be transmitted to the next generation. Muscle and nerve cells share the property of responding to electrochemical/environmental stimuli and thus are ideal epigenetic interfaces for transgenerational phenotypic modification, which may explain in part why imprinted genes are particularly involved in neural development.

\section{DNA methylation}

DNA methylation refers to the adding of a methyl group on a cytosine base. It occurs primarily in the context of CpG dinucleotides, which cluster in regions called $\mathrm{CpG}$ islands. ${ }^{14}$ ' $\mathrm{CpG}$ ' refers to regions of DNA where a cytosine nucleotide appears next to guanine nucleotide interconnected by phosphate. When cytosines in $\mathrm{CpG}$ dinucleotides are methylated to form 5 -methylcytosine, a gene can be turned off. CpG dinucleotides are rare in mammals $(\sim 1 \%)$, but $\sim 50 \%$ of gene promoters are linked to $\mathrm{CpG}$ islands which are often unmethylated in healthy cells. Cells become methylated in a tissue-specific and agespecific manner during development. Where DNA methylation occurs can be critical for its effect. DNA methylation (ie, adding methyl groups to a cytosine base, figure 1) at a gene's promoter is linked to silencing (ie, less gene expression); in contrast, DNA methylation outside the promoter region (eg, gene body) is sometimes associated with increased gene expression. In the case of genomic imprinting, hypermethylation of one of the two parental alleles leads to monoallelic expression (conceptually similar to gene-dosage reduction in X-inactivation, see figure 2). DNA methylation has been implicated in cancer, neurodevelopmental disorders and autoimmune diseases. ${ }^{15}$ Thus, if exercise can influence DNA methylation, it may be the mechanism that underpins the lower cancer rate in those who are physically active.

\section{DNA methylation, health and diverse disease states}

Cancer cells are characterised by a global loss of DNA methylation among growth enhancers; and the coordinated acquisition of hypermethylation at the $\mathrm{CpG}$ islands of tumour suppressor genes. Global hypomethylation occurs primarily at parasitic DNA regions of the genome. For example, the LINE family member L1 is hypomethylated in a variety of cancers, such as those of the breast and colon. ${ }^{16}$

Neurological disorders are also associated with epigenetic dysregulation (ie, reversed patterns of a normal DNA methylation profile). Specifically, dysregulation of DNA methylation occurs in several neurological diseases, giving rise to hypermethylated and hypomethylated $\mathrm{CpG}$ sites. FMR1 promoter hypermethylation occurs among individuals diagnosed with Fragile $\mathrm{X}$ syndrome. Rett syndrome, an X-linked neurological disease, is 
A

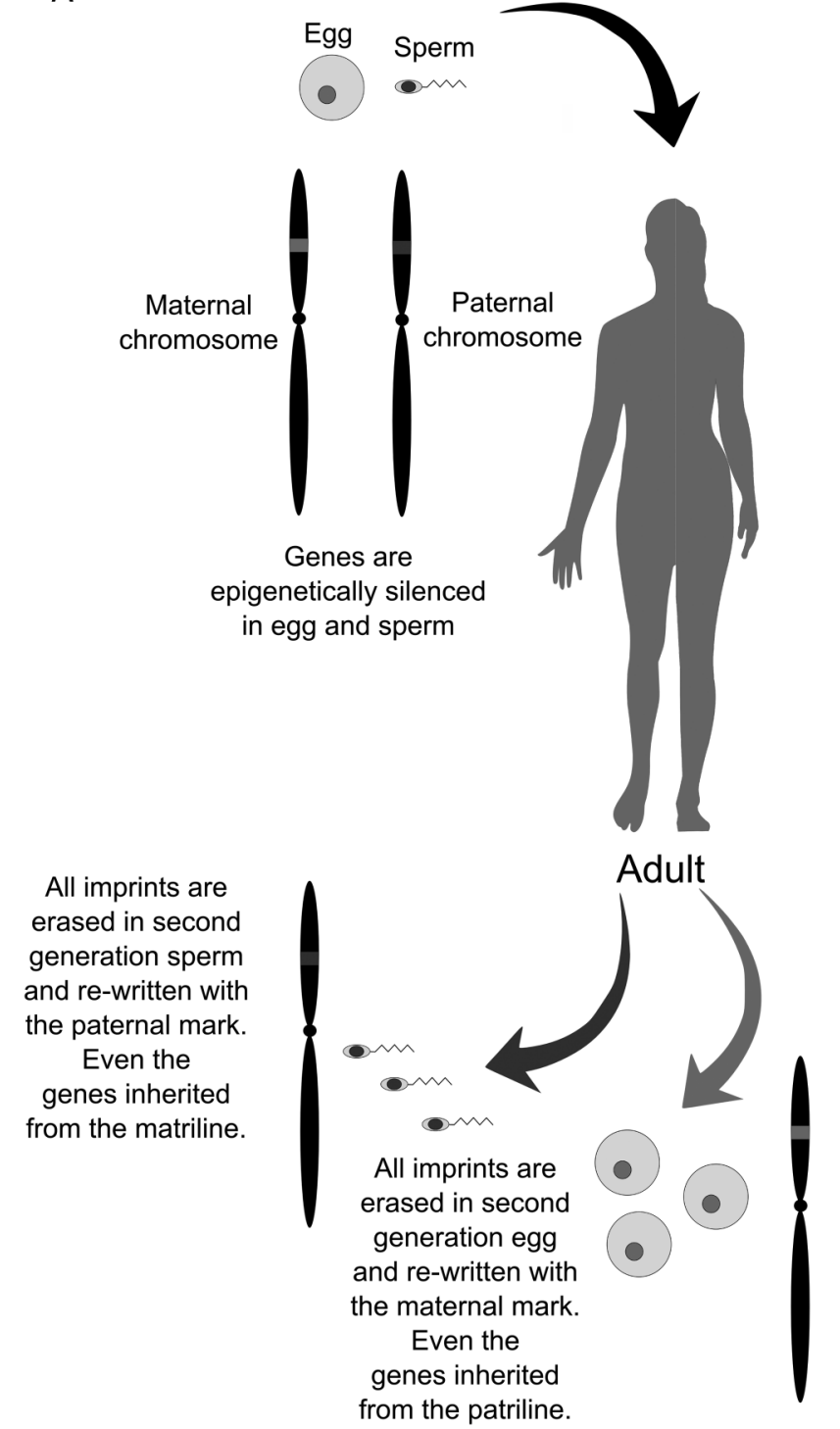

B

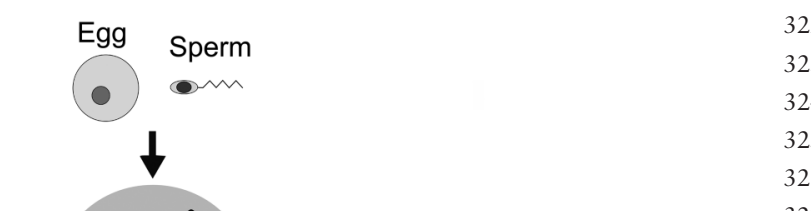

Parental $X$

chromosomes with orange phenotype allele
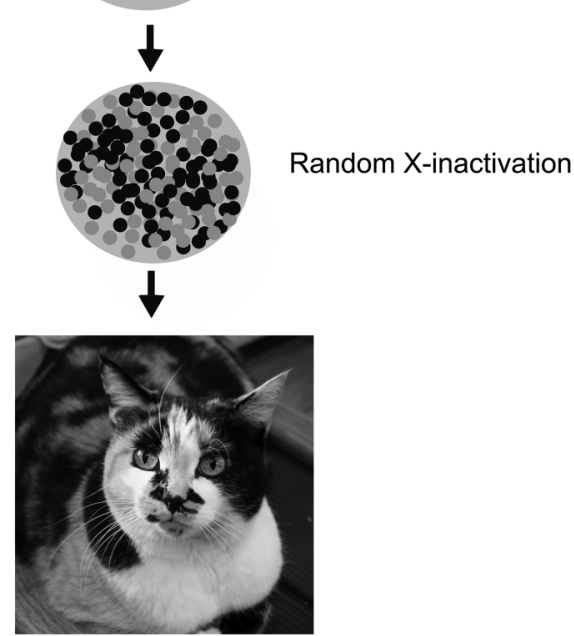

Mosaic calico female. Some cells express genes from the paternal $X$-chromosome, while others express genes from the maternal $X$-chromsome. A clone of this cat will yield a random reset of the epigenetic $X$-inactivation marks so that the clone's fur will not be identical to its parent.

Figure 2 (A) Genomic imprinting: Genomic imprinting is parent-of-origin (but genotype independent) gene expression. When males and females produce gametes (ie, sperm or eggs) an epigenetic mark (eg, DNA methylation, which silences one of the parental alleles) is placed on the DNA to indicate parent-of-origin. Regardless of sex of offspring imprinted genes affect growth and neural development differentially by parent-of-origin. Once the child produces its own gametes the imprints are erased and new parent-of-origin marks are established. Imprinted genes are rare but have profound effects on growth and neurodevelopment. (B) X-inactivation: X-inactivation is a process by which one parental copy of the X chromosome in women is randomly deactivated. $X$-inactivation prevents females from having twice as much $X$ chromosome gene production as males (which only have one copy of the $\mathrm{X}$ chromosome). Once the $\mathrm{X}$ chromosome is deactivated, it remains silent throughout the cell's lifetime. Compared with transcriptionally active $X$ chromosome, the inactive $X$ has higher levels of DNA methylation, which is associated with gene silencing. One difference between imprinting and $\mathrm{X}$-inactivation is the former is not random process with respect to which parental allele is epigenetically silenced.

caused by point mutations in MECP2, which encodes a methyl binding protein and is proposed to be a gene silencer. ${ }^{17}$

DNA methylation dysregulation is associated with autoimmune disease. For example, the Immunodeficiency Centromeric Instability and Facial Anomalies (ICFA) syndrome is caused by heterozygous mutations in DNMT3B. Individuals with ICFA show DNA hypomethylation among Alu repeats. Interestingly, despite patients with ICFA having normal global DNA methylation profiles, key developmental regulatory and immune function genes show loci-specific epigenetic dysregulation. $^{15}$

Whether it is cancers, neurological disorders or autoimmune disease, DNA methylation and imprinted genes are emerging causal factors. Some imprinted genes are involved in multiple phenotypes, ${ }^{18}$ suggesting that imprinting performs a regulatory function during ontogeny (eg, regulation of other genes).

The current paper argues that imprinted genes are important for skeletal muscle development and their phenotypic effects reflect an underlying ancestral tug of war between parental genomes over offspring growth and developmental trajectories.

\section{Imprinted genes and skeletal muscle gene networks:} growth suppression and enhancement

Imprinted genes are genes whereby an epigenetic mark is laid down during gametogenesis, indicating a key environmental source of information, the parental origin of a particular gene. There are few imprinted genes in the human genome, but they are often associated with growth, neural functioning and 
behaviour. Parental antagonism theory ${ }^{19}$ is currently the best theory for the phenotypic effects of growth regulators (eg, the paternal genome within offspring fosters growth at a cost to the maternal genome, while the maternal genome attempts to minimise these costs by suppressing growth).

Haig's mode ${ }^{19}$ proposes that imprinting evolved as a result of opposing fitness interests of parental genomes. For example, in polygamous species, patrigenes (genes expressed within offspring inherited from the father) favour fetal growth at the expense of depleting maternal resources and disadvantaging future offspring. Meanwhile, matrigenes (genes expressed within offspring inherited from the mother) will oppose the paternal effect and conserve resources to optimise inclusive fitness of the mother and future offspring. Haig's theory ${ }^{19}$ predicts that paternally expressed imprinted genes will often promote growth, while maternally expressed genes will have opposite effects to reduce costs on matrilineal inclusive fitness.

IGF2-an imprinted gene and paternally expressed in humans-regulates muscle development. IGF2 is upregulated early in MyoD-induced in myocyte differentiation and IGF2 inhibition leads to reduced expression of $M y o D$ target genes, which suggests that IGF2 is essential for amplifying and maintaining MyoD efficacy. ${ }^{20}$ IGF2's role as a paternally derived skeletal muscle growth enhancer is consistent with the theoretical orientation of this paper.

Germane to sports medicine, some imprinting disorders affect muscle growth. For example, Angelman (AS) and Prader-Willi syndromes (PWS) are imprinting disorders affecting muscle development and health. PWS is caused by an overexpression of maternal genes on chromosome 15 , while AS is due to an overexpression of paternal genes. Muscle biopsies of 11 PWS children have been investigated using histochemical and morphometric methods. ${ }^{21}$ The phenotypic abnormalities included (A) fibre size variation of both type 1 and 2 fibres, (B) type 2 fibre atrophy, (C) increased numbers of type $2 \mathrm{C}$ fibres and (D) decreased numbers of type $2 \mathrm{~B}$ fibre. This finding is consistent with the overexpression of maternal genes suppressing skeletal muscle growth. In addition to their low muscle tone, PWS individuals experience chronic hunger, potentially leading to overeating and obesity.

DNA methylation and imprinted loci influence muscle hypertrophy-extremely muscled hindquarters-in callipyge sheep. ${ }^{22}$ Hypomethylation of Clpg1 causes muscle hypertrophy, in part due to the overexpression of $D l k 1,{ }^{22}$ a paternally expressed imprinted gene associated with muscle precursor cell (myoblast) differentiation. ${ }^{23}$ DNA demethylation promotes skeletal myotube maturation. ${ }^{24}$ Early experiments in the 1970s showed that DNA methyltransferase inhibitors (eg, 5-azacytidine) induced transdifferentiation of fibroblasts into myoblasts. ${ }^{25}$ More recently, in $\mathrm{C} 2 \mathrm{C} 12$ culture, Hupkes et $\mathrm{l}^{24}$ noticed that on treatment with the methylation inhibitor (ie, 5 -azacytidine), myotubes spontaneously acquired repetitive membrane activity, intracellular calcium transients and contractility. Hupkes $e a^{24}$ suggested that DNA methylation may pose an epigenetic barrier to $\mathrm{C} 2 \mathrm{C} 12$ myotubes reaching maturity. However, when imprinted genes are involved in skeletal muscle development, the so-called 'DNA methylation barrier' will likely be parent-of-origin dependent. Beyond the distinct possibility that imprinted genes coordinate mammalian skeletal muscle development (eg, regulating skeletal muscle gene networks), it remains to be investigated whether the DNA methylation of imprinted loci are responsive to human exercise.

\section{Exercise epigenetics and DNA methylation}

Traditionally, exercise biologists envision biological systems changing by the regulation of protein synthesis (eg, alteration of receptor expression or intracellular signalling). Since transcription precedes translation, it is often at the level of the 'transcriptome' that adaptations can be tracked at the molecular level. Subtle changes in gene transcription occur through epigenetic regulatory machinery. A variety of epigenetic mechanisms allow for transcriptional activation and specification of cell identity, maintaining homoeostasis and responding to environmental conditions. These epigenetic mechanisms encompass DNA methylation, post-translational histone modifications and microRNA (figure 3). Much of the previous research on environmental epigenomics involves nutrition; however, exercise physiology is coming to the forefront. There is evidence that DNA methylation can change due to short bouts of exercise (eg, exercising to exhaustion ${ }^{26}$ ) and longer, more sustained exercise regimens (eg, 6 months of controlled walking ${ }^{27}$ ). For example, a high-intensity interval walking regimen increased DNA methylation of the proinflammatory gene ASC (apoptosis-associated speck-like protein containing a caspase recruitment domain) among older adults nearly to the levels of healthy younger adults. ${ }^{28}$ Among breast cancer sufferers, DNA methylation changes in L3MBTL1 (an imprinted and possible tumour suppressor gene) due to exercise (eg, brisk walking on treadmill) has been demonstrated. ${ }^{29}$

\section{Exercise epigenetics: research questions}

What is the average effect of exercise on changes in DNA methylation and does age, research design, sample size, sex or tissue heterogeneity influence the size of the effect? Are imprinted genes implicated in skeletal muscle gene networks and exercise-associated DNA methylation changes in humans? Since imprinted genes regulate adiposity, energy expenditure and glucose homoeostasis, it was hypothesised that imprinted genes will be involved in human skeletal muscle gene networks and targets of exercise-associated DNA methylation change. To test these hypotheses, gene ontology and meta-analytic methodologies were utilised.

\section{METHODS}

\section{A human skeletal muscle gene network: testing the importance of imprinted genes}

It is hypothesised that human skeletal muscle growth is regulated by imprinted genes. A gene ontology networking web server called g:Profiler ${ }^{30} 31$ was used to assess the functional involvement of imprinted genes for skeletal muscle gene networks. First, human skeletal muscle genes were determined using the Xavier laboratory gene enrichment profiler $^{32} 33$ (figure 4). To test the hypothesis that imprinted genes are implicated in skeletal muscle gene networks, g:Profiler ${ }^{30}$ was used. Human imprinted genes (29 maternally expressed and 57 paternally expressed) were selected from http://www.geneimprint. com. Imprinted genes were combined with 26 skeletal muscle genes (figure 4).

\section{Meta-analysis on exercise-associated DNA methylation change}

This meta-analysis was limited to English as no foreign language results were found. Only published papers measuring DNA methylation and exercise in humans were used. The following search strings were entered into PubMed (1968 to 2 May 2014): (1) 'DNA methylation and exercise'; and (4) 'DNA methylation and physical activity (human-only)'. Search results finalised by the author (figure 5). Both PRISMA (see online supplementary file 1) and MOOSE (see online supplementary file 2) guidelines 


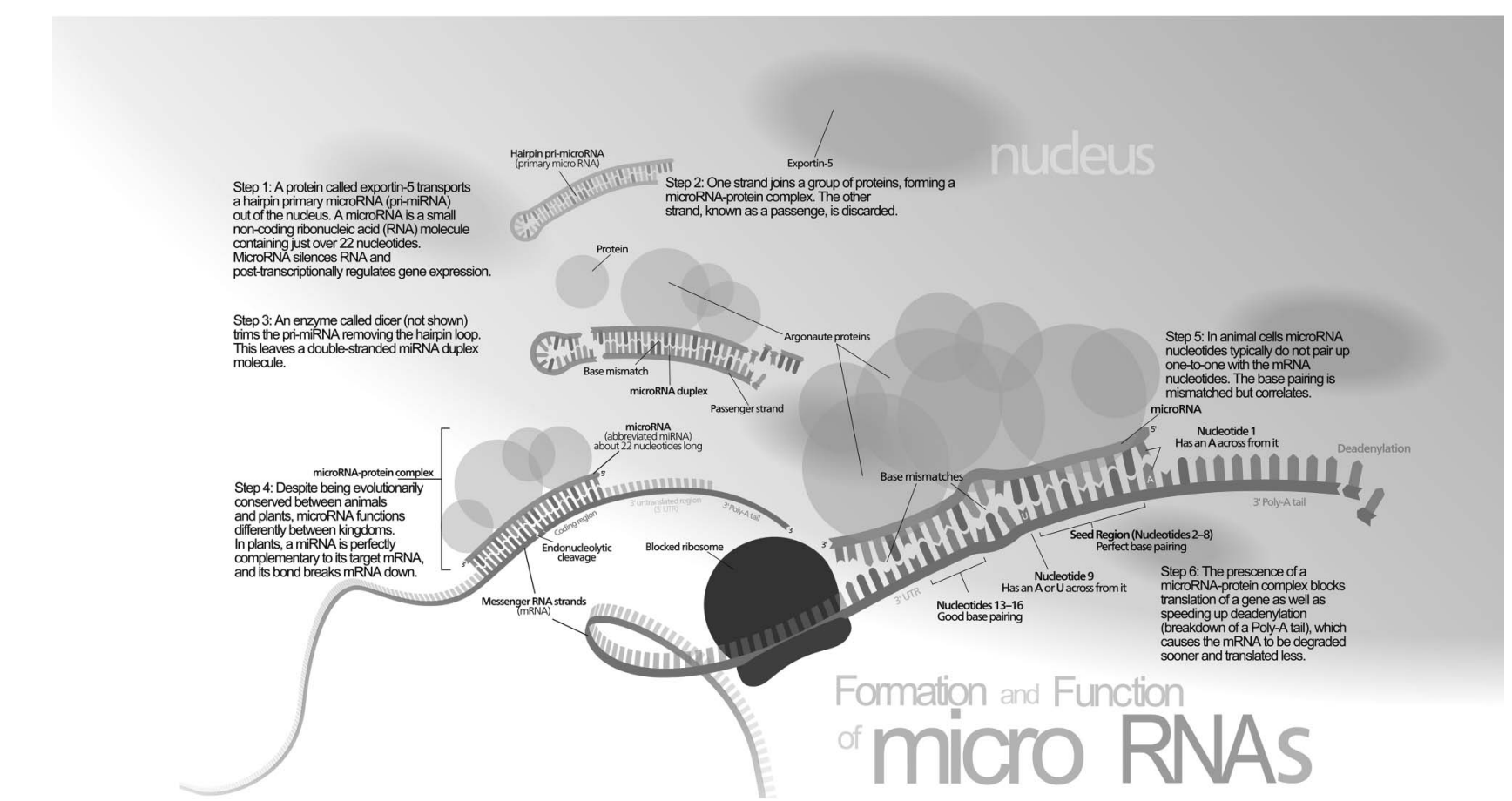

Figure 3 MicroRNAs (miRNAs): A miRNA is a small (ie, approximately 19 to 25 nucleotides in length) non-coding RNA molecule functioning to silence RNA and involved in the post-transcriptionally modification of gene expression. miRNA should not be confused with messenger RNA. miRNAs are another important molecular epigenetic regulator. miRNAs can result in small, but important reductions in physiologically relevant gene expression by blocking translation. Modified from Kelvin Song.

followed. One author did not respond to a direction of effect query. Reference lists did not yield additional articles.

\section{RESULTS}

\section{Imprinted genes and skeletal muscle gene networks}

Table 1 shows the imprinted genes associated with skeletal muscle gene networks. Six imprinted genes (ie, three maternally expressed genes RB1, MEG3 and UBE3A and three paternally expressed genes INS, PLAGL1 and SGCE) were revealed to be part of the gene networks of highly enriched skeletal muscle loci. Considering the rarity of imprinted genes in the human, this is biologically significant. Below is a description of each imprinted gene involved.

\section{Paternally expressed genes linked to muscle-related phenotypes}

1. Pleomorphic adenoma gene-like 1 (PLAGL1): As seen in table 1, PLAGL1 is part of two gene ontology networks: 'muscle organ development' (GO: 0007517) and 'skeletal muscle tissue development' (GO: 0007519). PLAGL1 encodes a zinc finger protein with transactivational and DNA-binding functions. PLAGL1 has antiproliferative properties making it a candidate for functioning as a tumour suppressor gene. Overexpression of this gene during fetal development underlies transient neonatal diabetes mellitus (TNDM). In most tissues (eg, skeletal muscle), PLAGL1 appears to be expressed from the paternal allele. ${ }^{34}$

2. Sarcoglycan, epsilon (SGCE): As seen in table 1, SGCE is part of a gene ontology network called 'muscle organ development' (GO: 0007517) and a human phenotype gene network called 'abnormality of the musculature of the neck' (HP: 0011006). SGCE encodes the epsilon member of the sarcoglycan family (ie, transmembrane proteins which are part of the dystrophin-glycoprotein complex linking the actin cytoskeleton to the extracellular matrix). Epsilon sarcoglycan is more broadly expressed (ie, not just restricted to striated muscle). Mutations in this gene are associated with the myoclonus-dystonia syndrome and it is imprinted (preferentially expressed from the paternal copy). ${ }^{34}$

3. Insulin (INS): As seen in table 1, INS is part of a human phenotype gene network called 'motor delay' (HP: 001270). The INS gene encodes for proinsulin (a prohormone precursor to insulin), which is post-translationally cleaved into three peptides. Binding of insulin to the insulin receptor (INSR) stimulates glucose uptake. A multitude of mutant alleles with phenotypic effects have been identified. Notably, INS-IGF2, a read-through gene, aligns to the INS gene, whereby INS is at the 5' region and IGF2-an extremely well-studied growth regulatory imprinted gene-is at the 3' region. ${ }^{34}$

\section{Maternally expressed genes linked to muscle-related phenotypes}

1. Retinoblastoma 1 (RB1): As seen in table $1, R B 1$ is part of two gene ontology networks: 'muscle organ development' (GO:0007517) and 'skeletal muscle tissue development' (GO:0007519). RB1 encodes a protein that negative regulates cell cycle and was the first tumour suppressor gene discovered. The encoded protein maintains overall chromatin structure. Defects in RB1 cause childhood retinoblastoma (RB), bladder cancer and osteogenic sarcoma. ${ }^{34}$

2. Maternally expressed 3 non-protein coding (MEG3): As seen in table $1, M E G 3$ is part of two gene ontology networks: 'muscle organ development' (GO: 0007517) and 'skeletal muscle tissue development' (GO: 0007519). MEG3 is expressed in many healthy tissues, but expression is lost in multiple cancer cell lines of various tissue types. Notably, MEG3 suppresses tumour cell proliferation in vitro and 
Figure 4 Enrichment profile for selected human skeletal muscle genes (defined as genes that have high enrichment scores within tissue and between tissues). Embryonic stem cells, $t$ cells, $b$ cells and myeloid gene loadings have been removed from heat map. $^{32} 33$
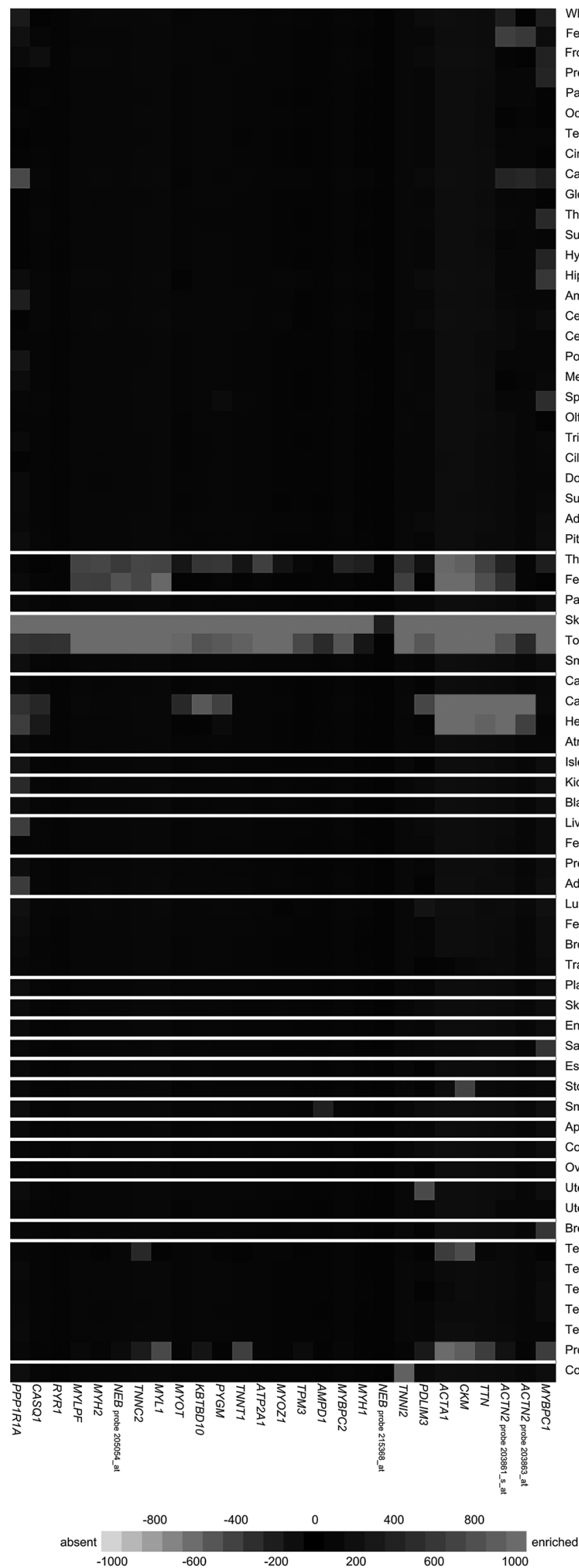

\section{3}

$-600$

$-200$

200

1000
Whole brain 705

Fetal brain $\quad 706$

Frontal cortex $\quad 707$

$\begin{array}{ll}\text { Prefrontal cortex } & 708\end{array}$

$\begin{array}{lr}\text { Parietal lobe } & 708 \\ \text { Occipital lobe } & 709\end{array}$

Temporal lobe $\quad 710$

Cingulate cortex $\quad 711$

$\begin{array}{ll}\text { Caudate nucleus } & 711 \\ \text { Globus pallidus } & 712\end{array}$

Thalamus $\quad 713$

Subthalamic nucleus $\quad 714$

$\begin{array}{ll}\text { Hypothalamus } & 714\end{array}$

$\begin{array}{ll}\text { Amygdala } & 716\end{array}$

$\begin{array}{ll}\text { Amygdala } & 716 \\ \text { Cerebellum } & 717\end{array}$

Cerebellum peduncles $\quad 718$

Pons

Medulla oblongata

Spinal cord

Olfactory bulb

Trigeminal ganglion

Ciliary ganglion

Dorsal root ganglion

Superior cervical ganglion

Adrenal gland

Pituitary

Thyroid

Fetal thyroid

Pancreas

Skeletal muscle

Tongue

Smooth muscle

Cardiac myocytes

Cardiac muscle left ventricle

Heart

Atrioventricular node $\quad 733$

Islet cells 734

Kidney

Bladder

Liver

Fetal liver

Preadipocyte subcutaneous

Adipocyte

Lung

Fetal lung

Broncho epithelial

Trachea

Placenta

Skin

Endothelial CD105+

Salivary gland

Esophagus

Stomach

Small intestine

Appendix

Colon

Ovary

Uterus

Uterus corpus

Breast

Testis

Testis leydig cel

Testis germ cell

Testis interstitial

Testis seminiferous tubule

Prostate

Conjunctiva 


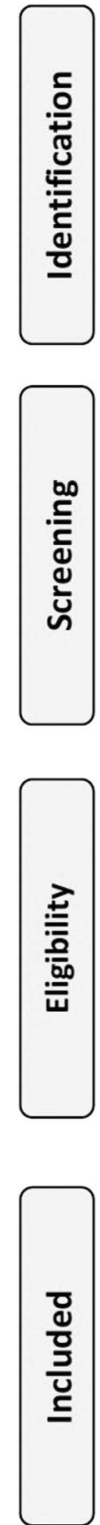

\section{Records identified through PubMed} search DNA methylation exercise ( $n=71)$

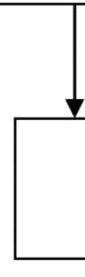

Records identified through PubMed search DNA methylation physical activity, human-restricted ( $\mathrm{n}=115$ )

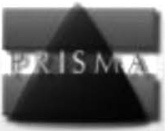

Records after duplicates removed $(n=166)$

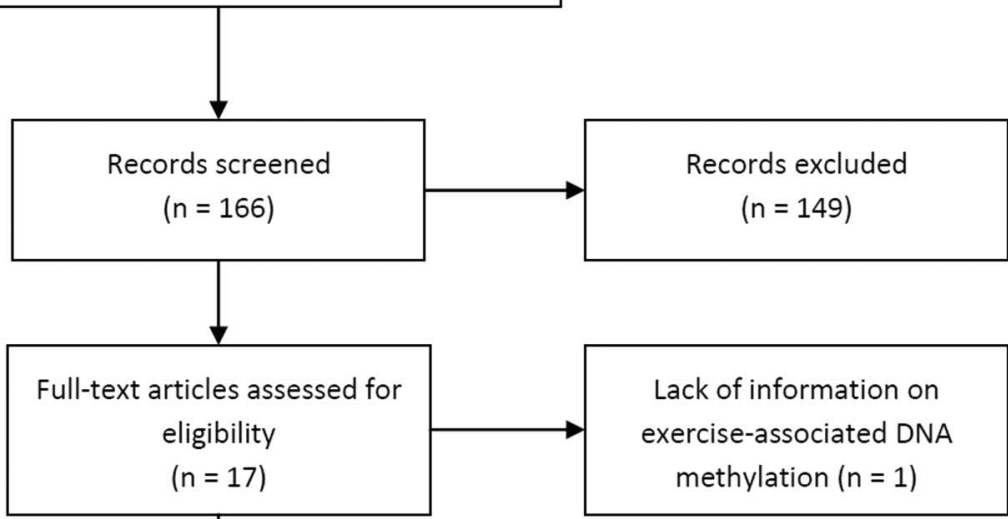

Studies included in quantitative synthesis (meta-

analysis, $n=16$ )

Figure 5 PRISMA flow diagram for meta-analysis component of paper. Search terms used were 'DNA methylation exercise' or 'DNA methylation physical activity'. Human in vivo studies only (May 2014).

interacts with tumour suppressor p53. Deleting MEG3 enhances angiogenesis in vivo. Many studies show that MEG3 is a long non-coding RNA tumour suppressor. ${ }^{34}$

3. Ubiquitin protein ligase E3A (UBE3A): As seen in table 1, $U B E 3 A$ is part of a human phenotype gene network called 'motor delay' (HP:001270). UBE3A encodes an E3 ubiquitin-protein ligase. This imprinted gene is maternally expressed in the brain and most likely biallelically expressed in skeletal muscle. Maternally inherited deletion of this gene causes a neurodevelopmental disorder AS which is characterised by severe motor and intellectual impairments, ataxia, hypotonia, epilepsy and absence of speech. UBE3A's protein in part causes ubiquitination and proteolysis of tumour protein $\mathrm{p} 53 .{ }^{34}$

\section{Meta-analysis of exercise-associated DNA methylation change}

To determine if there is a directional bias in exercise-associated methylation change, a binomial signed test was conducted.
Two-hundred and eighty-seven genetic elements (out of 478) showed significantly decreased DNA methylation after exercise (binomial test $\mathrm{p}<0.001$ ). Online supplementary table S2 reports the 478 genetic elements showing exercise-associated DNA methylation change, 5 of which are imprinted genes (maternally expressed (GRB10, KCNQ1, MEG3) and paternally expressed (PLAGL1, L3MBTL)). Despite appearing like a small percentage of imprinted loci, this is much higher than the expected number of 1-2 (ie, assuming there are 90 imprinted genes in a human genome containing $\sim 22300$ genes): binomial test $p<0.03$. All imprinted genes showed a decrease in DNA methylation after exercise, except for GRB10 and KCNQ1 (adipose tissue only).

Table 2 provides location, ontology and growth-related effects for the imprinted genes showing exercise-associated DNA methylation change. Unfortunately, it was not possible to determine if exercise-associated DNA methylation change in the imprinted loci was near differentially methylated regions (DMRs) as each imprinted gene in table 2 has clinically relevant single-nucleotide polymorphisms. Among the five imprinted 
Table 1 Imprinted genes networked with human skeletal muscle genes and network function

\begin{tabular}{|c|c|c|c|c|c|}
\hline Function & ID & p Value & Genes & PAT & MAT \\
\hline Muscle organ development & GO: 0007517 & 0.0005 & $\begin{array}{l}\text { PLAGL1, SGCE, RB1, MEG3, MYL1, NEB, ACTA1, } \\
\text { TTN, MYLPF, RYR1, CASQ1 }\end{array}$ & PLAGL1, SGCE & $R B 1, M E G 3$ \\
\hline Motor delay & HP: 001270 & 0.03 & UBE3A, INS, NDN, NEB, ACTA1, TTN, TNNT1, TPM3, RYR1 & INS & UBE3A \\
\hline Abnormality of the musculature of the neck & HP: 0011006 & 0.05 & SGCE, NEB, ACTA1, TTN, TPM3 & SGCE & - \\
\hline
\end{tabular}

genes revealed by the meta-analytic search in table 2, DNA was extracted from diverse tissues (ie, skeletal muscle, adipose and blood).

\section{Degree of exercise-associated DNA methylation change: effect of age and confounded factors}

The effect size of exercise on DNA methylation for the 478 genetic elements (387 were unique genes) across 16 different publications and 1580 people-see online supplementary table S2) - is large (mean Cohen's $d=1.20 \pm 1.20 ; 95 \%$ CI of the mean 1.10 to 1.31 ) and significantly different from a test value of zero (ie, no effect of exercise on DNA methylation): onesample $\mathrm{t}(477)=22.77, \mathrm{p}<0.001$. Analysis of covariance (ANCOVA) revealed that the effect size of exercise-associated DNA methylation change was significantly greater for people over 40 years of age (Cohen's $\mathrm{d}=2.89 \pm 1.97$ ) compared with those under 40 years of age (Cohen's $d=0.90 \pm .51)$ : $(F(1,471)$ $=197.26, p<0.001$, partial $\left.\eta^{2}=0.30\right)$. In this model, the effect of age was independent of research design (experimental designs' larger effect size, $\mathrm{p}<0.001$ ), sample size (smaller studies' larger effect sizes, $\mathrm{p}<0.001$ ), sex (larger effect size among females than males, $\mathrm{p}<0.03$ ) and tissue specificity (larger effect sizes in tissue with more cell types, $\mathrm{p}<0.001)$. The fact that sample size and effect size are significantly and negatively correlated suggests the presence of publication bias: $\mathrm{r}(477)=$ $-0.11 ; \mathrm{p}<0.02$. Sample size has been included as a covariate in analyses.

Online supplementary table S2 shows that most of the genes decreased in DNA methylation percentage after exercise (238/ 387 different genes). ANCOVA (sample size controlled) found a direction of change by age interaction: $F(1,381)=20.14$, $\mathrm{p}<0.001$, partial $\eta^{2}=0.05$. Specifically, among older people (people older than 40 years of age), the effect size was significantly larger $(\mathrm{p}<0.05)$ when DNA methylation increased with exercise $(3.85$; 95\% CI of the mean 3.32 to 4.38$)$ compared with when DNA methylation decreased with exercise (3.04,
95\% CI of the mean 2.45 to 3.63). However, the reverse was true for people under 40 years of age. Specifically, among younger people (people less than 40 years of age), the effect size was significantly smaller $(\mathrm{p}<0.05)$ when DNA methylation increased with exercise $(0.90 ; 95 \%$ CI of the mean 0.83 to $0.97)$ compared with when DNA methylation decreased with exercise $(1.00,95 \% \mathrm{CI}$ of the mean 0.95 to 1.05$)$.

To elucidate the possible function of this interaction among older people, the genes showing increases and decreases after exercise were exposed to g:Profiler ${ }^{30}$ for ontology analysis by age. As seen in table 3, among older people the genes that increased in DNA methylation after exercise were associated with growth regulation (GO:0022603), and the genes that become less methylated after exercise are targets of a putative tumour suppressing microRNA miR-519B. Two imprinted genes (L3MBTL1, PLAGL1)—both of which are tumour suppressors —are associated with miR-519b's microRNA network.

Among younger individuals, a microRNA-regulated gene network involved in stem cell activity was implicated. Specifically, as seen in table 4 , genes that increased in DNA methylation among younger people were part of a microRNA-regulated (hsa-miR-130b*) gene network that suppresses stem cell activity. Statistically significant (all $p$ values $<0.04)$ gene networks were uncovered for the genes that decreased in DNA methylation after exercise among younger people. Specifically, these gene networks are important for the biological processes of the extracellular matrix, skeletal muscle and cartilage development (table 4).

\section{Tissue heterogeneity}

Tissue type is a moderator of the degree of exercise-associated DNA methylation change. To further elucidate this apparent moderator, a one-way ANCOVA (controlling for sample size) was conducted and found significant: $F(4,471)=137.03$, $\mathrm{p}<0.001$, partial $\eta^{2}=0.54$ (figure $6 \mathrm{~A}$ ). As seen in figure $6 \mathrm{~A}$, exercise-associated DNA methylation change was greater in

Table 2 Imprinted genes that showed DNA methylation changes associated with exercise

\begin{tabular}{|c|c|c|c|c|c|c|}
\hline Gene & Ontology & Expression & Chromosome & Start & End & Growth \\
\hline PLAGL1 & Cell differentiation skeletal muscle; apoptosis & Paternal & 6 & 144328445 & 144328885 & Enhancer \\
\hline GRB10 & Insulin receptor pathway (negative regulation) & $\begin{array}{l}\text { Maternal skeletal muscle } \gamma \\
\text { splice variant }\end{array}$ & 7 & 50850662 & 50851107 & Suppressor \\
\hline KCNQ1 & $\begin{array}{l}\text { Cardiovascular system development; negative regulation of insulin } \\
\text { secretion; gene silencing }\end{array}$ & Maternal & 11 & 2465914 & 2870339 & Suppressor \\
\hline MEG3 & $\begin{array}{l}\text { Negative regulation of angiogenesis; cell proliferation, positive } \\
\text { regulation of skeletal muscle fibre development }\end{array}$ & Maternal & 14 & 101293947 & 101294390 & Suppressor \\
\hline L3MBTL & Regulation of megakaryocyte differentiation & Paternal & 20 & 42142508 & 42142820 & Enhancer \\
\hline
\end{tabular}

Function, parent-of-origin, differentially methylated region (DMR) location and hypothesised growth effects. Location of DMRs courtesy of Randy Jirtle. For KCNQ1, the DMR ${ }^{48}$ resides in intron 10. Genome Reference Consortium Human Build 37 (GRCh37). 
Table 3 Genes that showed exercise-associated increases (http://tinyurl.com/methincreased) and decreases (http://tinyurl.com/methdecreased) in DNA methylation among older people

\begin{tabular}{|c|c|c|c|c|}
\hline Change & Function & ID & p Value & Genes \\
\hline $\begin{array}{l}\text { Increased DNA methylation after } \\
\text { exercise }\end{array}$ & $\begin{array}{l}\text { Regulation of anatomical structure } \\
\text { morphogenesis }\end{array}$ & G0:0022603 & 0.018 & $\begin{array}{l}\text { CXCL10,DCC, PPP2R3A, RASA1,SULF1,TMEM100, } \\
\text { WNT7A }\end{array}$ \\
\hline $\begin{array}{l}\text { Decreased DNA methylation after } \\
\text { exercise }\end{array}$ & $\begin{array}{l}\text { microRNA } 519 \text { inhibits cell proliferation } \\
\text { and decreases tumour growth }\end{array}$ & Ml:hsa-miR-519b-3p & 0.016 & GAB1,L3MBTL1, PLAGL1, WNK3,BCL2L11,CACNA2D3 \\
\hline
\end{tabular}

Gene networks courtesy g:Profiler. ${ }^{30} 31$

GO, gene ontology; MI, computationally predicted microRNA target sites from the MicroCosm database (formerly miRBase).

blood samples compared with all tissue types (ie, buccal and salvia, breast and adipose, skeletal muscle and gastric tumour). For three out of five tissue types, the effect sizes are large. For buccal cells and saliva and gastric tumours, the effect sizes were medium.

\section{Exercise type}

Exercise type is a potential moderator of the degree of DNA methylation change. To further elucidate the effect of exercise type on the degree of DNA methylation change, a one-way ANCOVA (controlling for sample size) was conducted and found significant: $F(2,453)=126.11, p<0.001$, partial $\eta^{2}=0.36$ (figure 6B). As seen in figure 6B, DNA methylation change was significantly greater among those engaged in Tai Chi and walking compared with those engaged in cycling. Walking and Tai Chi were not significantly different from one another $(p=0.25)$. Regardless of the specific type of exercise, effect sizes were large.

\section{DISCUSSION}

\section{Imprinted genes and skeletal muscle gene networks}

As predicted, imprinted genes were implicated in skeletal muscle gene networks. Table 1 is consistent with the hypothesis that parental genomes act simultaneously to suppress and promote skeletal muscle growth. The argument is that for skeletal muscle the maternal genes in table 1 (RB1, MEG3 and UBE3A) suppress growth, while paternal genes (INS, PLAGL1 and SGCE) perform antagonistic functions (ie, growth enhancement).

Some imprinted genes expected based on non-human animal research were conspicuously absent from the human skeletal muscle gene networks. For example, in sheep, imprinted gene
H19 regulates muscle development. ${ }^{35}$ H19 is also known as ASM for 'adult skeletal muscle'. H19 is a negative regulator of prenatal growth and bovine muscle development. ${ }^{35}$ H19 is maternally expressed at high levels in embryonic and fetal skeletal muscle and is located closely downstream of paternally expressed IGF2 performing antagonistic functions (ie, growth enhancement).

Beyond H19, other imprinted genes studied in non-human animals were absent from the human skeletal muscle gene networks, such as DLK1, which is a well-known imprinted gene and paternally expressed muscle growth enhancer. In mouse skeletal muscle cultures, the genetic ablation of Delta-like 1homolog (Dlk1) causes reductions in skeletal muscle mass, in part due to myofiber number loss and myosin heavy chain IIB gene expression. ${ }^{36}$ GRB10 was another imprinted gene missing from g:Profiler's human skeletal muscle gene networks. In mice, Grb10 has a tissue-dependent imprinting status (ie, paternally expressed in the brain and maternally expressed in muscle, see Garfield $e t a l^{37}$ for its links to behaviour). Holt et $a l^{38}$ have found evidence that when Grb10 is deleted, hypermuscularity overgrowth occurs, suggesting that maternal gene expression functions to suppress muscle growth. The same pattern occurs in human skeletal muscle. ${ }^{39}$

Considering the rarity of imprinted genes, it is remarkable that six imprinted genes were discovered as part of skeletal muscle gene networks. Imprinted genes most likely repress, maintain and induce muscle-specific transcription during myogenesis. Future studies should investigate epigenomic antagonisms between paternally and maternally derived genes during myogenesis, as opposed to assuming that decreased methylation invariably leads to growth. Owing to the importance of

Table 4 Genes that showed exercise-associated increases and decreases (http://tinyurl.com/methdecreases-young) in DNA methylation among younger people

\begin{tabular}{|c|c|c|c|c|}
\hline Change & Function & ID & p Value & Genes \\
\hline $\begin{array}{l}\text { Increased DNA methylation } \\
\text { after exercise }\end{array}$ & Regulation of stem cell activity & MI: hsa-miR-130b* & 0.008 & $\begin{array}{l}\text { SNCG,NCOA6, MRPS26, SPINT4,HDACC3, ESR2, TSTD1,RGS6,FHL1, } \\
\text { ANO2 }\end{array}$ \\
\hline $\begin{array}{l}\text { Increased DNA methylation } \\
\text { after exercise }\end{array}$ & Negative regulation of cell cycle & G0:0045786 & $<0.02$ & $\begin{array}{l}\text { FHL1,RB1,RPTOr,ZFHX3,CAB39,CDK9,HDAC3,MED25, PSMC5, } \\
\text { BRCA1, RUNX3 }\end{array}$ \\
\hline $\begin{array}{l}\text { Decreased DNA methylation } \\
\text { after exercise }\end{array}$ & $\begin{array}{l}\text { Extracellular structure } \\
\text { organisation; extracellular matrix } \\
\text { organisation }\end{array}$ & $\begin{array}{l}\text { G0:0043062, } \\
\text { G0:0030198 }\end{array}$ & $<0.02$ & $\begin{array}{l}\text { LTBP4, COL15A1, COL18A1,COL4A1,LAMA2,NID1, NRXN1, } \\
\text { OLFML2A,PTK2,SFRP2,SULF2,COMP,FBLN2 }\end{array}$ \\
\hline $\begin{array}{l}\text { Decreased DNA methylation } \\
\text { after exercise }\end{array}$ & $\begin{array}{l}\text { System development; skeletal } \\
\text { system development; cartilage } \\
\text { development }\end{array}$ & $\begin{array}{l}\text { G0:0048731, } \\
\text { G0:0001501, } \\
\text { G0:0051216 }\end{array}$ & $<0.04$ & $\begin{array}{l}\text { PRKG1,ALDH1A2, ANK3,ANKS1A, BATF,CAMK2B, CASP8,CD74, } \\
\text { CENPF,CHL1, COL15A1, COL18A1,COL4A1,DKK3,EHD1,EYA1,FLG, } \\
\text { HDAC9,HYAL2,IL7,IPMK,KCNQ1, KERA,LAMA2, LFNG,LILRB1, LMO4, } \\
\text { LY6D, MBNL1,MEF2A, MEPE,MITF,NFIB, ND1,NNMT, NPR2,NRXN1, } \\
\text { PLXND1, PTK2,RUNX1,SCIN,SERPINI1,SFRP2,SIX6,SLC35D1, SULF2, } \\
\text { TRPV4, TTLL7,CHRDL2, COMP,PAX6, RUNX3,SIM1 }\end{array}$ \\
\hline
\end{tabular}

Gene networks courtesy g:Profiler. ${ }^{30} 31$

GO, gene ontology; MI, computationally predicted microRNA target sites from the MicroCosm database (formerly miRBase). 
A

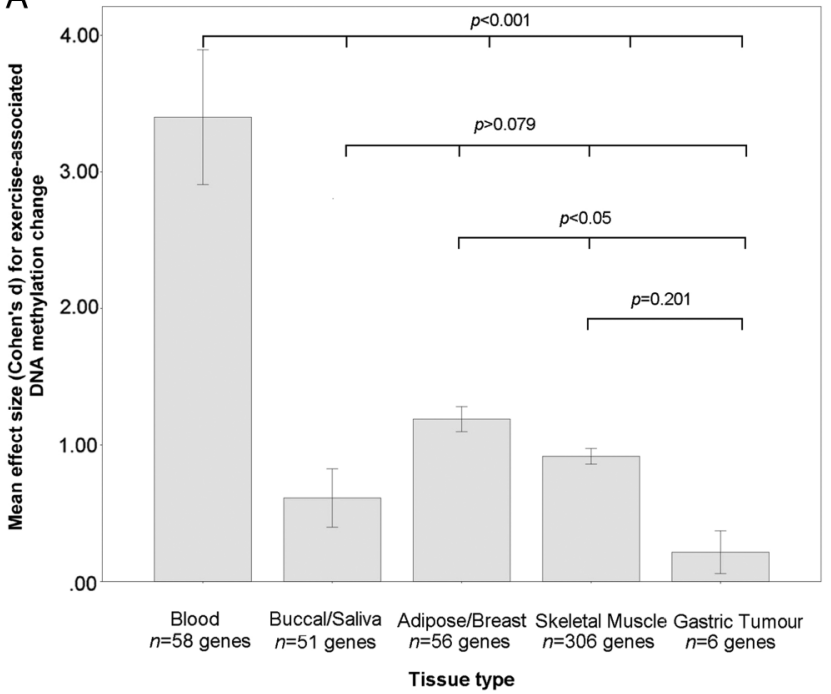

B

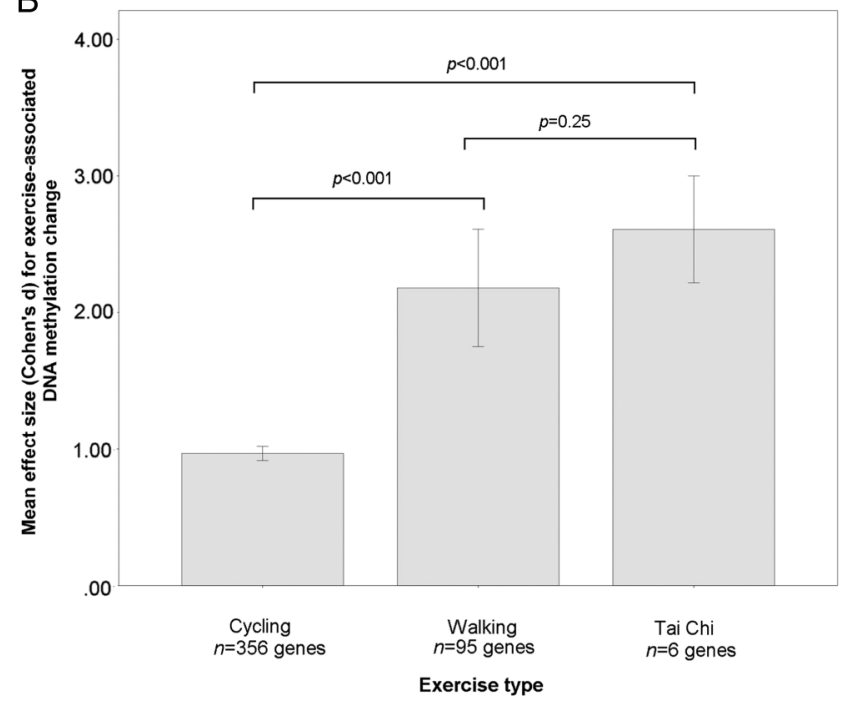

imprinted genes for skeletal muscle development (table 1), it was hypothesised that imprinted genes would be implicated in exercise-associated DNA methylation changes. These findings are discussed below.

\section{Exercise-associated DNA methylation change}

Human exercise has medium to large effect sizes on the DNA methylation of genes extracted from different tissues across sex and lifespan. The effect sizes are strong among older people above and beyond the independent effects of research design, sample size, sex and tissue type. Publication bias is possible and difficult to rule out. However, the correlation between effect size and sample size was small $(\mathrm{r}=-0.11)$ and driven in part by two studies, both of which were tightly controlled molecular exercise physiology experiments with small sample sizes and large effect size. The large effect size in these studies could be due to methodological rigour. Nonetheless, sample size and other moderating factors were included in the analyses, suggesting that exercise has substantial effects on DNA methylation. Since this work was limited to published studies from western cultures, file drawer artefacts are a potential source of bias. Future work will need to investigate cultural and geographical effects, which could bias the findings. Given the plasticity of human development and population genetic variation, we may expect regional variation in the size of exercise-associated DNA methylation change.

As expected, imprinted genes-a DNA methylation-based transgenerational epigenetic phenomenon-are responsive to exercise exposure. Recall the skeletal muscle gene network analyses revealed both maternally expressed (RB1, MEG3, UBE3A) and paternally expressed (PLAGL1, SGCE, INS) imprinted genes likely played growth regulatory functions. Likewise, the meta-analysis imprinted genes showed changes in DNA methylation associated with exercise. Specifically, maternally expressed (GRB10, KCNQ1, MEG3) and paternally expressed (L3MBTL1, PLAGL1) genes were represented in the meta-analysis. Sixty per cent of the 478 genetic elements uncovered in the meta-analysis showed decreased DNA methylation after physical exercise. Among older people, the genes that increased in DNA methylation were involved in growth, while the genes that decreased in
DNA methylation were part of the cancer-suppressing microRNA gene network. This strongly suggests that exercise may have a protective function among older people, perhaps shielding them to a degree from the age-related diseases and decline.

It is notable that two of the six genes that decreased in DNA methylation among older people after exercise (ie, L3MBTL1, PLAGL1) are imprinted targets of tumour suppressor microRNA miR-519b. Considering that imprinted genes (eg, hypermethylation of tumour suppressors) are often associated with diverse forms of cancer, this is both a biologically and medically important finding. Exercise-associated decreases in L3MBTL1 DNA methylation are associated with decreased mortality among patients with breast cancer. ${ }^{29}$ Exercise-associated decreases in CACNA2D3 (also included in the microRNA network reported here) DNA methylation may help reduce gastric tumorigenesis. ${ }^{40}$ These findings suggest that, at least for older people, exercise could have a protective effect against a variety of cancers in both sexes. More experimental approaches (ie, a mouse transfection model) likewise suggest that miR-519b suppresses breast cancer. ${ }^{41}$ The ability of the miR-519b network to inhibit cell proliferation and decrease tumour growth ${ }^{42}$ makes it potentially an epigenetically labile network for clinical researchers interested in exercise. In contrast, among younger people (less than 40 years of age), a microRNA-regulated (hsa-miR-130b*) gene network, which functions to suppress stem cell proliferation, increased in DNA methylation after exercise.

The fact that exercise-associated DNA methylation change was stronger in older compared with younger people indicates that exercise could alter an organism's 'epigenetic age' by warding off senescence. Why would exercise have more profound effects on older compared with younger epigenomes? One possibility is that as organisms age, epigenetic errors accumulate, and because there are more to correct or reset, older people experience greater (and more positive) DNA methylation change compared with younger people (who have experienced fewer epigenetic errors). Since physically active grandparents were probably a characteristic of the majority of human evolution, the pronounced age effect could also be an example 
of an age-dependent adaptive epigenetic response to antagonistic pleiotropy. Antagonistic pleiotropy is the hypothesis that genes with multiple effects can be beneficial at younger ages and costly later in life. In the context of growth effects, older individuals' tumour suppressor genes were becoming demethylated (possibly more expressed), but growth-related loci were becoming methylated (presumably less expressed). Thus, rebuilding new tissue would become increasingly costly for older people relative to younger people. To reiterate, stem cells and tissue regeneration adaptive gene complexes in younger people may well be costly among older age groups due to cancer proliferation and premiums on cancer suppression as we age. Please note that reverse antagonistic pleiotropic effect may be operating here, that is, growth suppression among younger individuals may be particularly costly (eg, inability to regenerate or develop costly secondary sexual characteristics) relative to older postreproductive individuals. The effect of age was independent of tissue type effects. Specifically, it was found that exercise-associated DNA methylation changes are greater in blood compared with breast, adipose and skeletal muscle tissues. This latter result is consistent with the hypothesis that epigenetic dysregulation in more heterogeneous samples (eg, blood)-compared with a single tissue sample-may be a better proxy for the accumulation of environmental stress as we age. Beyond repeated exposure of physical exercise across the lifespan being important for a healthy epigenome, in utero maternal epigenetic effects are likely to be important.

There is recent work in mice showing that maternal exercise during pregnancy can reverse the deleterious epigenetic effects of poor maternal diet on newborn pups' $P g c-1 a .{ }^{43}$ The beneficial effects of maternal exercise during pregnancy on Pgc-1a DNA methylation levels in the next generation suggest that a transgenerational mechanism exists for long-lasting epigenetic changes and is consistent with a fetal origins of disease approach. ${ }^{44}$ There is no evidence of transgenerational DNA methylation effects of exercise in humans. ${ }^{44}$ However, it is noteworthy from the meta-analysis that GRB10 ( $\gamma$ isoform)-maternally expressed in human fetal skeletal muscle ${ }^{39}$ - showed greater exercise-associated DNA methylation change among those without a type 2 diabetes family history. Relaxation of the growth-inhibiting effects of maternal genes could be dependent on genetic, ecological conditions or fetal exposure to maternal exercise. For example, individuals from families exhibiting more sedentary behaviour (ie, characterised by a history of type 2 diabetes) have less silencing of maternally expressed GRB10 in skeletal muscle. Such differentially epigenetic responses of GRB10's $\gamma$ isoform depending on a family history of type 2 diabetes would be extremely interesting if reliable. A powerful interface between family history and offspring epigenetic could be signalled during gestation. Specifically, maternal exercise during gestation could produce dose-dependent epigenetic responses in offspring. $^{43}$

Despite using two different methods (ie, g-Profiler gene ontology network analysis vs meta-analysis), multiple imprinted loci appear to be missing. This raises the distinct possibility that additional imprinted genes will be found to be associated with muscle adaptation and exercise adaptation in humans. For example, in newborns with transient neonatal diabetes, the loss of an epigenetic mark at the TNDM locus on chromosome 6 q24 in the mesodermal lineage causes abdominal muscle hypoplasia, the so-called prune belly sequence. ${ }^{45} 46$ When Laborie et $a l^{47}$ investigated a family with prune belly that included one discordant set of $\mathrm{MZ}$ twins, the twin with prune belly (relative to the normal co-twin) had extensive loss of methylation at the
TNDM locus, as well as at the following imprinted loci IGF2R, DIRAS3 and PEG1. Future work in humans and other animals should be able to develop a more comprehensive list of imprinted genes regulating skeletal muscle and associated with exercise. One reason that some imprinted genes may be missed from these analyses could be due to the fact that imprinted genes are often involved in neural systems, ${ }^{18}$ which, unlike skeletal muscle, cannot be extracted from healthy human participants.

Future work needs to be conducted to test whether or not imprinted DMRs ${ }^{48}$ are modified by exercise. Once again, given the relevance of imprinted genes for human cancers, one longstanding conundrum in medicine could be resolved. Specifically, why does exercise treatment appear to reduce the incidence of cancers? One answer is that tumour suppressor genes are 'reactivated' at promoters on long-term exercise treatment and the corresponding reduction in DNA methylation. ${ }^{29}$ Given these possible medical benefits, future research should look at the relationship between exercise stress and regulation of imprinted genes in order to understand more fully the underlying mechanisms.

It is worth noting that exercise-associated DNA methylation changes for imprinted genes occurred only in studies where participants were exposed to longer term exercise (ie, 6 months) as opposed to short bouts of exercise. This interpretation should be taken with caution as it is biased by the fact that fewer genes were studied in the acute study by Barrès et $a l^{26}$. Specifically, Barrès et $a l^{26}$ selected genes from a previous study of DNA methylation in patients with type 2 diabetes, while the longterm exercise studies revealing the imprinted genes (see online supplementary table 2) screened many more genes using Illumina's Infinium HumanMethylation450 BeadChip (San Diego, California, USA).

\section{CONCLUSIONS}

Modern epigenomics helps to end nature-nurture debates over health and disease. The genome is sensitive to the environment and environmental information is encoded into the epigenome transgenerationally (eg, imprinted genes). Rather than argue which is more important, nature or nurture, we can now measure the interface between the two directly. Measuring the interface between genes and the environment (eg, DNA methylation) will have ramifications for health and human disease due to an ageing and an increasingly physically inactive population. Given the increasing amount of research from multiple independent laboratories ${ }^{26-29} 49-40$ indicating that human exercise has varied associations and effects on DNA methylation, it is a reasonable hypothesis that long-term exercise throughout the lifespan (or exposure during sensitive periods of in utero development) could have profound effects on the epigenome. ${ }^{44}$ Future work should determine the optimal exercise types, timing and duration for ameliorating epigenetic-based disease outcomes. The strength of exercise-associated DNA methylation change could be an overestimate due to publication bias (eg, unpublished studies not included). Genetic background could affect the associations reported here and was not ruled out. Future work should sample from monozygotic twins reared together and apart to elucidate the importance of genetic background. To rule out publication bias, a collection of unpublished exercise epigenetics papers will need to be collected and analysed.

Uncovering epigenetic biomarkers is likely to be more clinically relevant than looking for 'disease genes' because epigenetic changes can be reversed and also since disease variants are 
1409 expected to be at low frequency due to the power of natural 1410 selection to remove deleterious genetic variants from a popula1411 tion. Techniques are being developed to remove epigenetic 1412 marks (ie, DNA demethylation), which can radically change 1413 disease phenotypes (eg, tumour progression). Exercise medicine 1414 should work alongside clinical epigenetics to investigate how 1415 exercise shapes the human epigenome. An applied goal would 1416 be to adaptively decouple chronological and epigenetic age by 1417 using exercise interventions. The analyses presented here 1418 suggest that exercise-associated DNA methylation change 1419 reduces epigenetic age (eg, cancer reduction ${ }^{29}{ }^{40}$ ). Controlled 1420 exercise interventions could help the ageing epigenome, espe1421 cially among older hospitalised patients. For example, one study 1422 of older people (aged 58-90 years) with cerebrovascular disease 1423 suggests that physical function improvements during hospitalisa1424 tion covary with subtelomeric methylation of long telomeres. ${ }^{59}$

1425 If exercise alters the epigenome to reduce age-related disease 1426 outcomes, it could be a relatively inexpensive treatment option 1427 within hospital environments. In conclusion, human studies in 1428 exercise epigenetics are required not only because of the impact 1429 on health of ageing populations, but also because key epigenetic 1430 elements (ie, imprinted genes) responsible for regulating adipos1431 ity, energy expenditure, glucose homoeostasis and hunger are 1432 differentially imprinted (or read differently) between mice and 1433 man.

\section{What is already known on this subject}

Recent empirical studies suggest that physical exercise modifies the human epigenome. Specifically, DNA methylation-an important regulator of gene expression and correlate of diverse disease states-is altered by physical activity. No systematic review has been conducted to elucidate these effects and associations.

\section{What this study adds}

This study isolates imprinted genes-known to be important for health and disease-as important for muscle growth and clinical targets of exercise. Further, older people received significant benefits from exercise in terms of the adaptive epigenetic regulation of tumour suppressor genes.

\section{Twitter Follow William Brown at @coevolve}

Acknowledgements Thanks to Randy Jirtle, John Brewer, Thomas Chalk, Javaid Kashani and Louis Metcalf for discussions of the ideas presented here. Alex Forcellati (BSC), Ryan Lenton and Meishan Raal-Nunes (MSc) helped compile information provided in online supplementary table $S 2$. WMB's research time was supported by the European Office of Aerospace Research \& Development FA8655-10-1-3037.

\section{Competing interests None.}

Provenance and peer review Not commissioned; externally peer reviewed.

\section{REFERENCES}

1 Waddington CH. The epigenotype. Endeavour 1942;1:18-20.

2 Haig D. The (dual) origin of epigenetics. Cold Spring Harb Symp Quant Bio 2004:69:67-70.

3 Nanney DL. Epigenetic control systems. Proc Natl Acad Sci USA 1958;44:712-17.
4 Killian JK, Nolan CM, Wylie AA, et al. Divergent evolution in M6P/IGF2R imprinting from the Jurassic to the Quaternary. Hum Mol Genet 2001;10:1721-8.

5 Abramowitz LK, Bartolomei MS. Genomic imprinting: recognition and marking of imprinted loci. Curr Opin Genet Dev 2012;22:72-8.

6 Morison IM, Paton CJ, Cleverley SD. The imprinted gene and parent-of-origin effect database. Nucleic Acids Res 2001;29:275-6.

7 Jirtle R. [Internet]. Gene Imprint; c2012. http://geneimprint.com/site/ genes-by-species

8 Eggermann T. Silver-Russell and Beckwith-Wiedemann syndromes: opposite (epi) mutations in 11p15 result in opposite clinical pictures. Horm Res 2009:2:30-5.

9 Kong A, Steinthorsdottir V, Masson G, et al. Parental origin of sequence variants associated with complex diseases. Nature 2009:462:868-74.

10 Buiting K. Prader-Willi syndrome and Angelman syndrome. Am J Med Genet C Semin Med Genet 2010;154C:365-76.

11 Monk D, Arnaud P, Frost J, et al. Reciprocal imprinting of human GRB10 in placental trophoblast and brain: evolutionary conservation of reversed allelic expression. Hum Mol Genet 2009;18:3066-74.

12 Mackay DJ, Temple IK. Transient neonatal diabetes mellitus type 1. Am J Med Genet C Semin Med Genet 2010;154C:335-42.

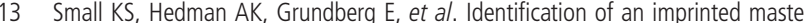
trans regulator at the KLF14 locus related to multiple metabolic phenotypes. Nat Genet 2011;43:561-4.

14 Deaton AM, Bird A. CpG islands and the regulation of transcription. Genes Dev 2011;25:1010-22

15 Portela A, Esteller M. Epigenetic modifications and human disease. Nat Biotechnol 2010:10:1057-68.

16 Cruickshanks HA, Tufarelli C. Isolation of cancer-specific chimeric transcripts induced by hypomethylation of the LINE-1 antisense promoter. Genomics 2009;6:397-406.

17 Hite KC, Adams VH, Hansen JC. Recent advances in MeCP2 structure and function. Biochem Cell Biol. 2009:87:219-27.

18 Dent $C L$, Isles AR. Brain-expressed imprinted genes and adult behaviour: the example of Nesp and Grb10. Mamm Genome 2014;25:87-93.

19 Haig D. The kinship theory of genomic imprinting. Annu Rev Ecol Syst 2000:31:9-32

20 Wilson EM, Rotwein P. Control of MyoD function during initiation of muscle differentiation by an autocrine signaling pathway activated by insulin-like growth factor-II. J Biol Chem 2006;281:29962-71.

21 Sone S. Muscle histochemistry in the Prader-Willi syndrome. Brain Dev Jpn 1994;16:183-8.

22 Murphy SK, Nolan CM, Huang Z, et al. Callipyge mutation affects gene expression in cis: a potential role for chromatin structure. Genome Res 2006:16:340-6.

23 Bassel-Duby R, Olson EN. Signaling pathways in skeletal muscle remodeling. Annu Rev Biochem 2006;75:19-37.

24 Hupkes $\mathrm{M}$, Jonsson MK, Scheenen WJ, et al. Epigenetics: DNA demethylation promotes skeletal myotube maturation. FASEB J 2011;25:3861-72.

25 Taylor SM, Jones PA. Multiple new phenotypes induced in 10T1/2 and 3T3 cells treated with 5-Azacytidine. Cell 1979;17:771-9.

26 Barrès R, Yan J, Egan B, et al. Acute exercise remodels promoter methylation in human skeletal muscle. Cell Metab 2012:15:405-11.

27 Rönn T, Volkov P, Davegårdh C, et al. A six months exercise intervention influences the genome-wide DNA methylation pattern in human adipose tissue. PLoS Genet 2013;9:e1003572.

28 Nakajima K, Takeoka M, Mori M, et al. Exercise effects on methylation of ASC gene. Int J Sports Med 2010:31:671-5.

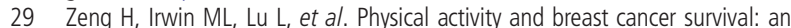
epigenetic link through reduced methylation of a tumor suppressor gene $L 3 M B T L 1$. Breast Cancer Res Treat 2012:133:127-35.

30 Reimand J, Kull M, Peterson $\mathrm{H}$, et al. g:Profiler a web-based toolset for functional profiling of gene lists from large-scale experiments. Nucleic Acids Res 2007;35 W193-200.

31 Reimand J, Arak T, Vilo J. g:Profiler-a web server for functional interpretation of gene lists. Nucleic Acids Res 2011;39:W307-315.

32 Benita Y, Cao Z, Giallourakis C, et al. Gene enrichment profiles reveal T-cell development, differentiation, and lineage-specific transcription factors including ZBTB25 as a novel NF-AT repressor. Blood 2010;115:5376-84.

33 Xavier RJ. [Internet]. Enrichment Profiler; c2013. http://xavierlab2.mgh.harvard.edu/ EnrichmentProfiler/

34 Xiang R, Ghanipoor-Samami M, Johns WH, et al. Maternal and paternal genomes differentially affect myofibre characteristics and muscle weights of bovine fetuses at midgestation. PLOS ONE 2013;8:e53402.

35 RefSeq [Internet]. NCBI; c2014. http://www.ncbi.nlm.nih.gov/refseq/

36 Waddell JN, Zhang P, Wen Y, et al. DIk1 is necessary for proper skeletal muscle development and regeneration. PLOS ONE 2010;5:e15055-0.

37 Garfield AS, Cowley M, Smith FM, et al. Distinct physiological and behavioural functions for parental alleles of imprinted Grb10. Nature 2011;469:534-8.

38 Holt LJ, Turner N, Mokbel N, et al. Grb10 regulates the development of fiber number in skeletal muscle. FASEB J 2012:26:3658-69. 
39 Blagitko N, Mergenthaler S, Schulz U, et al. Human GRB10 is imprinted and expressed from the paternal and maternal allele in a highly tissue- and isoform-specific fashion. Hum Mol Genet 2000;9:1587-95.

40 Yuasa $Y$, Nagasaki $H$, Akiyama $Y$, et al. DNA methylation status is inversely correlated with green tea intake and physical activity in gastric cancer patients. Int J Cancer 2009;124:2677-82.

41 Navarro P, Ramkissoon SH, Shah S, et al. An indirect role for oncomir-519b in the expression of truncated neurokinin-1 in breast cancer cells. Exp Cell Res 2012:318:2604-15

42 Abdelmohsen K, Srikantan S, Tominaga K, et al. Growth inhibition by miR-519 via multiple p21-inducing pathways. Mol Cell Biol 2012;32:2530-48

43 Laker RC, Lillard TS, Okutsu M, et al. Exercise prevents maternal high-fat diet-induced hypermethylation of the Pgc-1a gene and age-dependent metabolic dysfunction in the offspring. Diabetes 2012;63:1605-11.

44 Chalk TEW, Brown WM. Exercise epigenetics and the fetal origins of disease. Epigenomics 2014;6:469-72.

45 Mackay DJ, Hahnemann JM, Boonen SE, et al. Epimutation of the TND locus and the Beckwith Wiedemann syndrome centromeric locus in individuals with transient néonatal diabetes mellitus. Hum Genet 2006;119:179-84.

46 Mackay DJG, Boonen SE, Clayton-Smith J, et al. A maternal hypomethylation syndrome presenting as transient neonatal diabetes mellitus. Hum Genet 2006;120:262-9.

47 Laborie LB, Mackay DJ, Temple IK, et al. DNA hypomethylation, transient neonata diabetes, and prune belly sequence in one of two identical twins. Eur J Pediatr 2010;169:207-13.

48 Mancini-DiNardo D, Steele SJ, Ingram RS, et al. A differentially methylated region within the gene Kcnq1 functions as an imprinted promoter and silencer. Hum Mol Genet 2003;12:283-94.

49 Nitert MD, Dayeh T, Volkov $\mathrm{P}$, et al. Impact of an exercise intervention on DNA methylation in skeletal muscle from first-degree relatives of patients with type 2 diabetes. Diabetes 2012:61:3322-32.
50 Bryan AD, Magnan RE, Hooper AE, et al. Physical activity and differential methylation of breast cancer genes assayed from saliva: a preliminary investigation. Ann Behav Med 2013;45:89-98.

51 Coyle YM, Xie XJ, Lewis CM, et al. Role of physical activity in modulating breast cancer risk as defined by $A P C$ and RASSF1A promoter hypermethylation in nonmalignant breast tissue. Cancer Epidemiol Biomarkers Prev 2007;16:192-6.

52 Ren $\mathrm{H}$, Collins V, Clarke SJ, et al. Epigenetic changes in response to tai chi practice: a pilot investigation of DNA methylation marks. Evid Based Complement Altern Med 2012:2012:841810.

53 White AJ, Sandler DP, Bolick SC, et al. Recreational and household physical activity at different time points and DNA global methylation. Eur J Cancer 2013:49:2199-206.

54 Zhang FF, Cardarelli R, Carroll J, et al. Physical activity and global genomic DNA methylation in a cancer-free population. Epigenetics 2011;6:293-9.

55 Zhang FF, Santella RM, Wolff M, et al. White blood cell global methylation and IL- 6 promoter methylation in association with diet and lifestyle risk factors in a cancer-free population. Epigenetics 2012;7:606-14.

56 Luttropp K, Nordfors L, Ekströ TJ, et al. Physical activity is associated with decreased global DNA methylation in Swedish older individuals. Scand J Clin Lab Invest 2013;73:184-5.

57 Gomes MV, Toffoli LV, Arruda DW, et al. Age-related changes in the global DNA methylation profile of leukocytes are linked to nutrition but are not associated with the MTHFR C677T genotype or to functional capacities. PLoS ONE 2012;72: e52570.

58 Morabia A, Zhang FF, Kappil MA, et al. Biologic and epigenetic impact of commuting to work by car or using public transportation: a case-control study. Prev Med 2012;54:229-33.

59 Maeda T, Oyama J, Higuchi Y, et al. The physical ability of Japanese female elderly with cerebrovascular disease correlates with the telomere length and subtelomeric methylation status in their peripheral blood leukocytes. Gerontology 2011;57:137-43. 


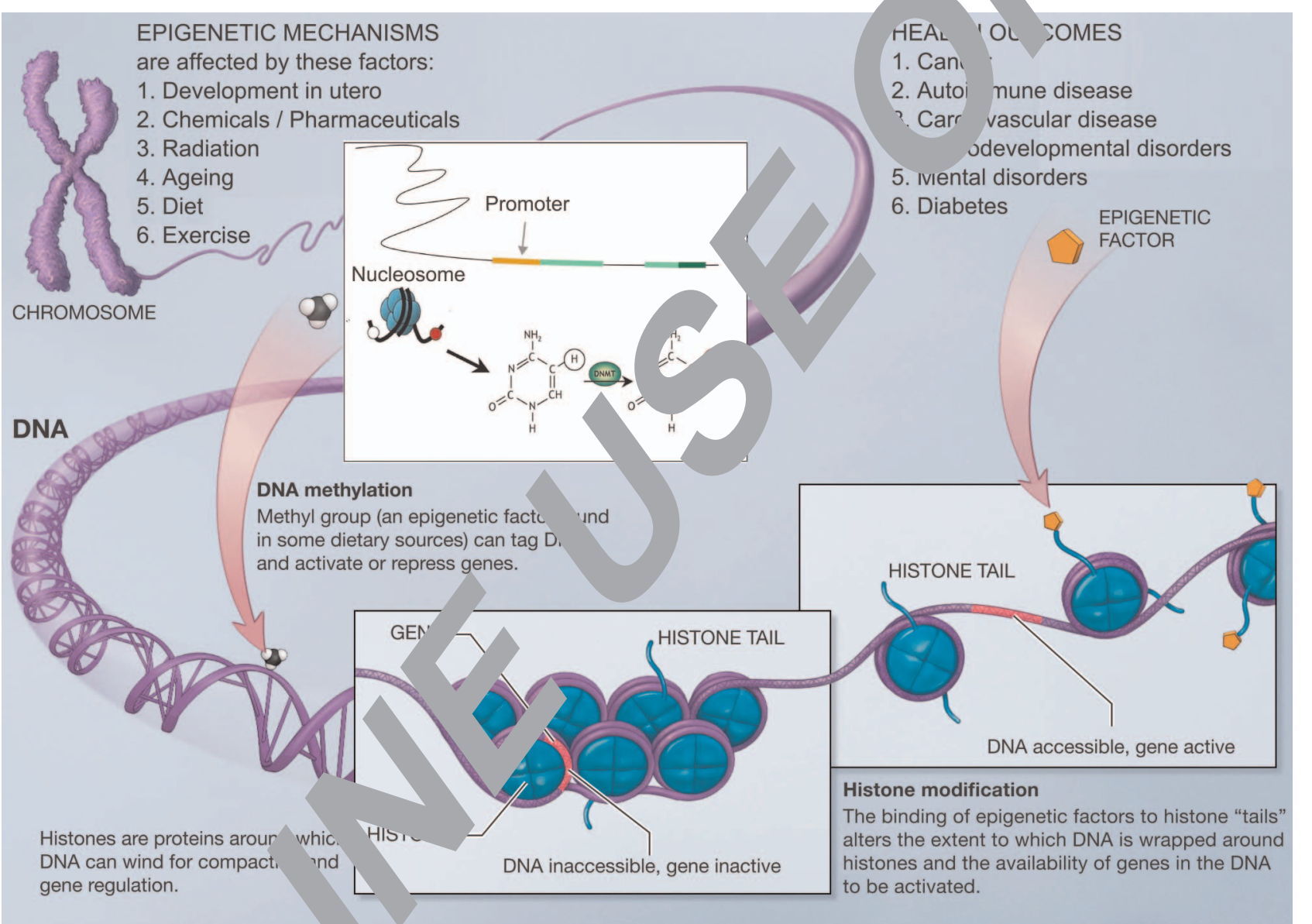


A

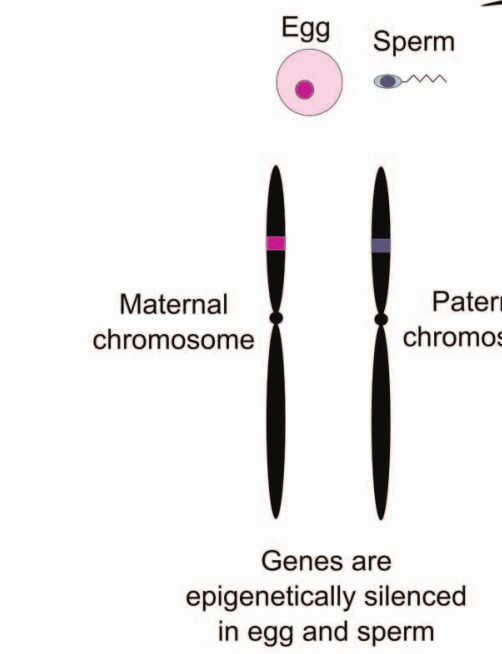

B

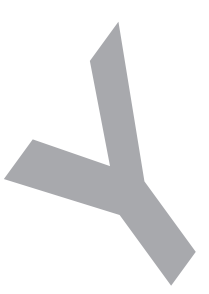

on

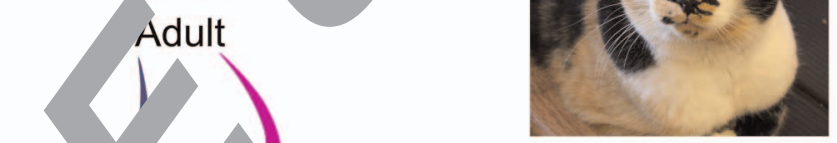

Mosaic calico female. Some cells express genes from the paternal X-chromosome, while others express genes from the maternal $\mathrm{X}$-chromsome. A clone of this cat will yield a random reset of the epigenetic X-inactivation marks so that the clone's fur will not be identical to its parent. 


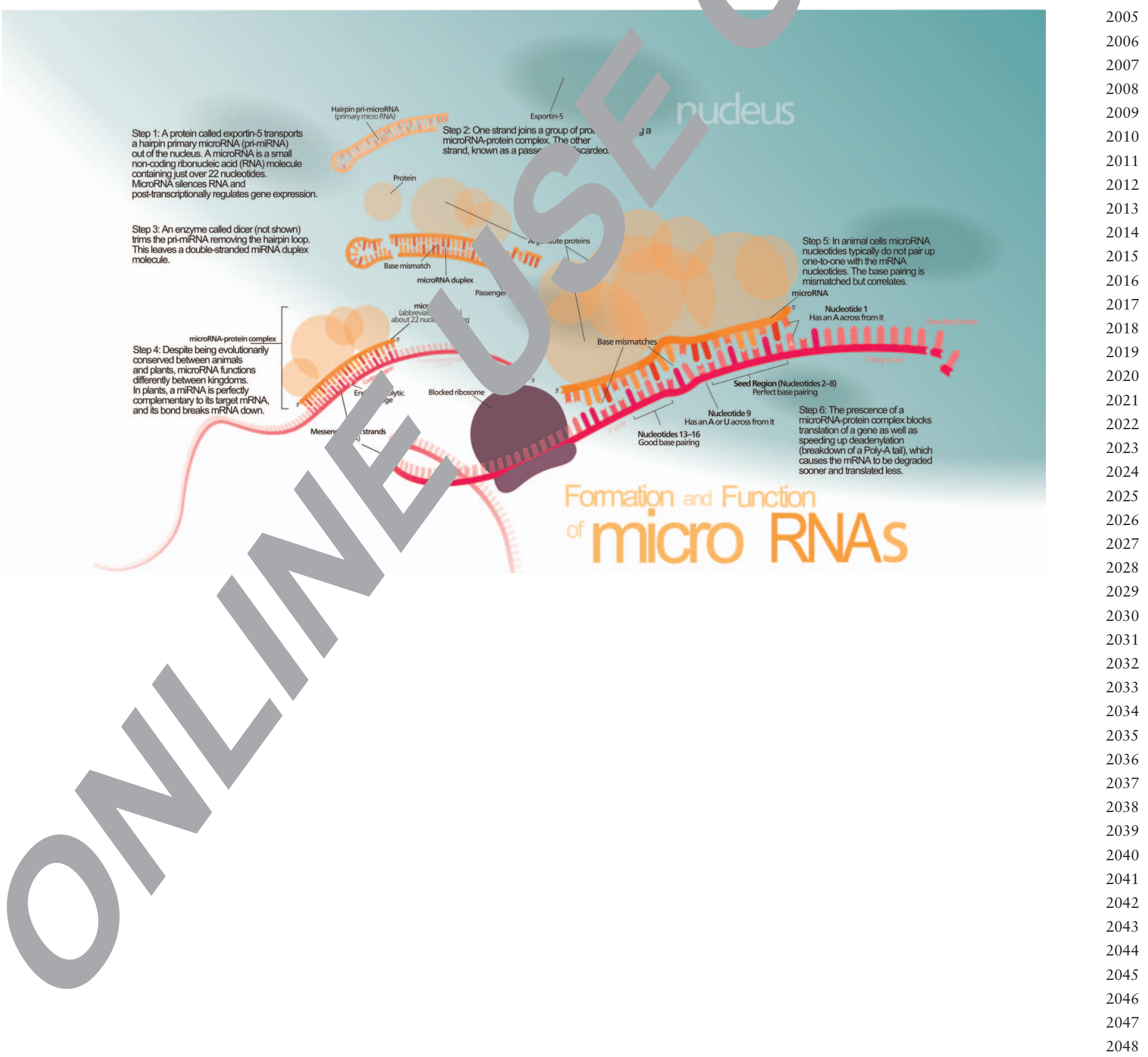




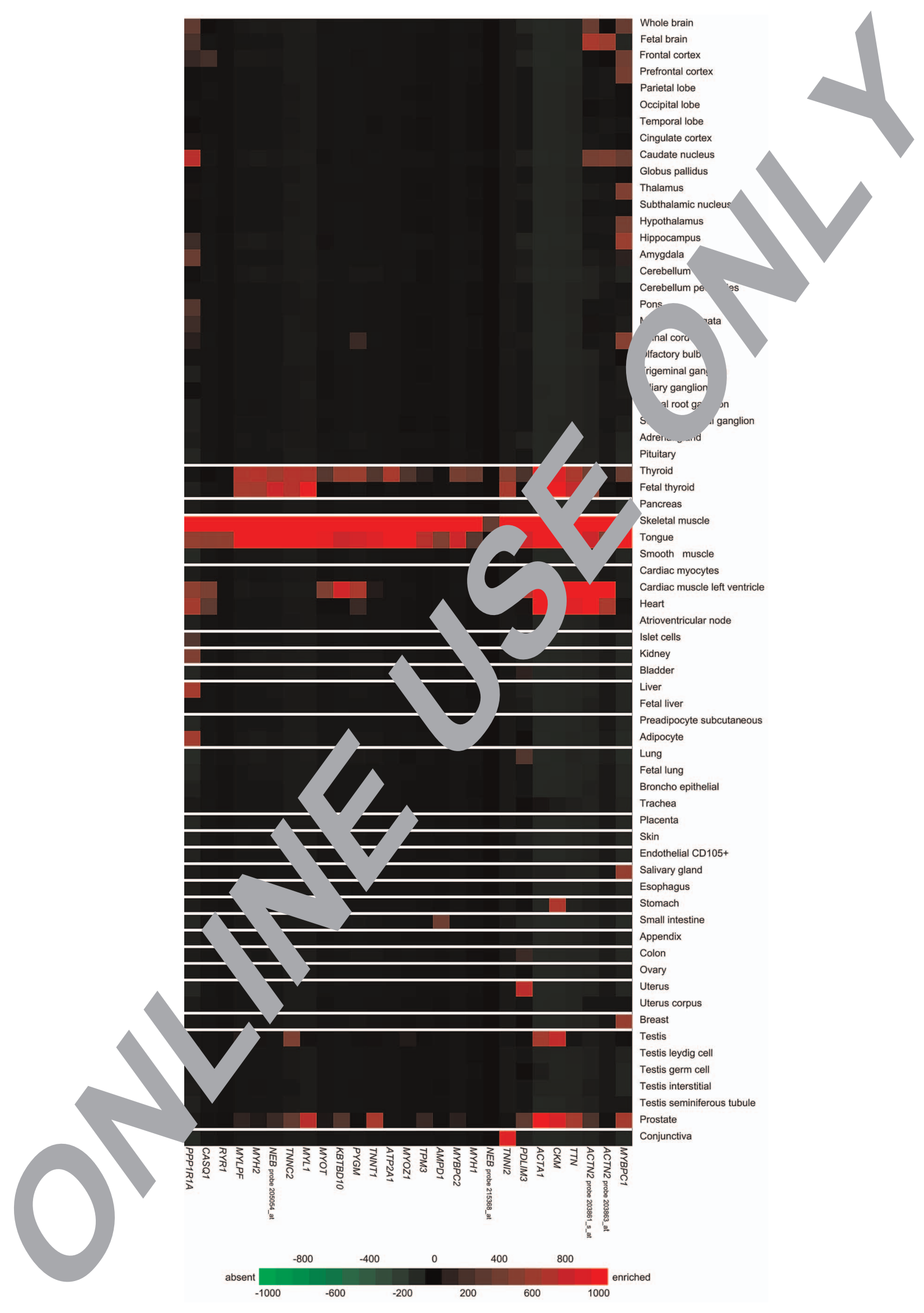


Records identified through PubMed search DNA methylation exercise $(n=71)$

Records after duplicates removed
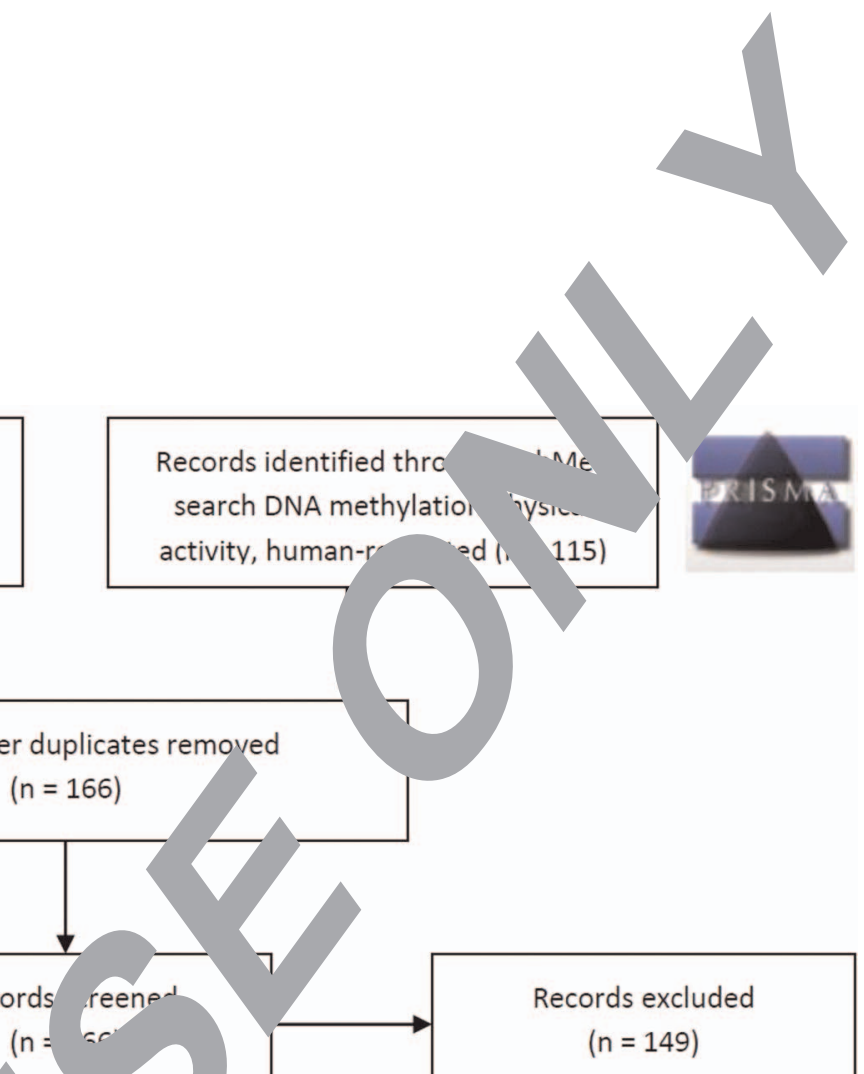
$(n=149)$

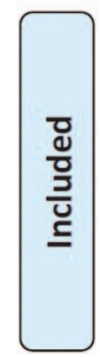

Lack of information on exercise-associated DNA methylation $(n=1)$ 